\title{
Malnutrition amongst Under-Five Years Children in Swat, Pakistan: Prevalence and Risk Factors
}

\author{
H Ullah ${ }^{1}$, B Ullah ${ }^{2}$, S Karim ${ }^{3}$, I Tariq ${ }^{3}$, AK Khan ${ }^{4}$, S Mir ${ }^{4}$, A Baseer ${ }^{1}$, S Azhar ${ }^{1}$ and \\ G Murtaza ${ }^{1 *}$ \\ ${ }^{1}$ Department of Pharmacy, COMSATS Institute of information Technology, Abbottabad 22060, ${ }^{2}$ Department of Surgery, Saidu \\ Teaching Hospital, Swat, ${ }^{3}$ University College of Pharmacy, University of Punjab, Lahore, ${ }^{4}$ Department of Chemistry, COMSATS \\ Institute of information Technology, Abbottabad 22060, Pakistan
}

*For correspondence: Email: gmdogar356@gmail.com; Tel: +92-314-2082826; Fax: +92-992-383441

Received: 17 May 2014

Revised accepted: 14 July 2014

\begin{abstract}
Purpose: To identify malnourished cases and determine their relationship with weaning time and socioeconomic factors in under-5 children in Swat, Pakistan.

Methods: This cross-sectional study was conducted at the Pediatric Ward and Outpatients Department (OPD), Saidu Teaching Hospital, Swat, Pakistan using case files from October to December 2011.

Results: A total of 186 children were studied to identify malnutrition, out of which 101 (37.7\%) were male and 85 (32.0\%) female. Moreover, 95 (35.7\%) of the mothers were < 30 years of age and 91 $(34.0 \%)>30$ years. About $33.7 \%$ of the children were weaned before the age of 4 months. The maternal age of $28.6 \%$ of the malnourished children was $<20$ years, and about $21 \%$ of the malnourished children were not immunized against eight EPI (Expanded Program on Immunization) target diseases, viz, poliomyelitis, neonatal tetanus, measles, diphtheria, pertussis (whooping cough), hepatitis- $B$, Hib pneumonia \& meningitis, and childhood tuberculosis. Respondents from urban location 98 (36.7\%), while 88 (33.0\%). Based on Gomez's classification, out of 186 children, 19 (7.1\%) were victims of malnutrition; mothers of $35.6 \%$ of the children were uneducated and $25.5 \%$ had primary level (5 years) education. The number of siblings per mother was $\geq 5$ in the case of $64.8 \%$ of the malnourished children. More than half of the children were at risk of malnutrition.

Conclusion: The incidence of malnutrition is about the same for both male and female children. Risk factors for malnutrition in the children include lack of education, teenage pregnancy, lack of immunization, and large family size.
\end{abstract}

Keywords: Malnutrition, Gomez's classification, Weaning time, Risk factors, Teenage pregnancy, Swat

Tropical Journal of Pharmaceutical Research is indexed by Science Citation Index (SciSearch), Scopus, International Pharmaceutical Abstract, Chemical Abstracts, Embase, Index Copernicus, EBSCO, African Index Medicus, JournalSeek, Journal Citation Reports/Science Edition, Directory of Open Access Journals (DOAJ), African Journal Online, Bioline International, Open-J-Gate and Pharmacy Abstracts

\section{INTRODUCTION}

Malnutrition is defined as a pathological state resulting from absolute or relative deficiency or excess of one or more of the nutrients that are considered essential for normal life [1]. Primary malnutrition is due to lack of primary health care and other social or environmental factors, and secondary malnutrition is due to the presence of some basic pathological conditions. Malnutrition is considered to be one of the foremost causes of morbidity and mortality in children throughout the world $[2,3]$.

About $30-40 \%$ of children in Pakistan have low height-for-age, this condition is called stunting. While $14 \%$ children shows low weight-for-height which is called wasting. According to report of 
the United Nation International Children Emergency Fund (UNICEF), 2 in every 5 children having age under-five years, in Pakistan are considered to be malnourished and 3 , out of every 5 children of under- five year age are stunted. Malnutrition remains a chief problem that is related to public health in Pakistan [4].

In 1868 , out of 8.8 million deaths of under-five years of age throughout the world, $93 \%$ were reported to be in the developing countries of Africa and Asia. Greater mortality rates in children occurred in sub-Saharan Africa, where 1 out of 7 children died $<4$ years [5].

Assessment of malnutrition can be made by so many ways such as anthropometry, dietary intakes, clinical observations, blood biochemistry tests, and other biochemical markers. Anthropometry refers to the measurement of human morphology or body dimensions and proportions [6].

Anthropometric indices, including weight-for-age, height-for-age and weight-for-height are most often employed to assess malnutrition in children [6]. The percentage of malnourished children continues to rise at the age from 6 months to 2 years and thereafter plateaus [7]. Each year, almost $53 \%$ out of 11 million deaths in children under the age of five years are due to malnutrition [8]. Based on Gomez's classification [9], $39.45 \%$ of malnourished children suffer first degree, $37.1 \%$ from second degree and $23.45 \%$ from third degree malnutrition in Bahawalpur, Pakistan [10]. In Karachi, the prevalence of malnutrition is $37.7 \%$ and females are twice more vulnerable to malnutrition than males [11]. Thus, the objective of this study was to identify malnourished cases and explore their relationship with weaning, breast feeding and socioeconomic factors of the children.

\section{EXPERIMENTAL}

The study was cross-sectional study was conducted using case files at the Pediatric Ward and Outpatients Department (OPD) of Saidu Teaching Hospital, Swat, Pakistan from October 10 to December 10, 2011 after approval from the Department of Community Medicines, Saidu Medical College, Swat. A consent form was filled and signed by all respondent mothers. All children, who were of age 1 to 5 years of either gender, were included. Those $<1$ year and $>5$ years were excluded from this study. Furthermore, those children who were born with congenital abnormalities were also excluded from this study. A total of 186 children were observed for the presence of malnutrition. The mid arm circumference, weight, height and head circumference of the children were measured. Weaning time and breast feeding were also inquired. Family size, immunization status, father education and maternal age of the children were also inquired. The malnourished children were classified on the basis of Gome's classification $[9,10]$.

\section{Data analysis}

The data were computed and analyzed using Statistical Package for Social Sciences (SPSS, version 16) and descriptive analysis was conducted. The results of each item in the questionnaire were reported as percentage and frequency. Chi - square test was used to test the significance of association between the independent variables (age, gender, education, weaning time) and the dependent variables (malnutrition). Statistical significance was set at $p$ $<0.05$.

\section{RESULTS}

A total of 186 children were studied for detection of malnutrition. Out of which, 101 (37.7\%) were male and $85(32.0 \%)$ were female. Moreover, 91 $(34.1 \%)$ mothers were educated, small number (35.6 \%) of mothers were uneducated. Respondents from urban location 98 (36.7 \%), while 88 (33.0\%). As mentioned in Table 1, 33.7 $\%(n=90)$ children are weaned before the age of 6 months. According to Gomez's classification, $19(7.1 \%)$ children were the victims of malnutrition. While $14.2 \%$ of children were suffering from moderate, while $48.3 \%$ of children lied in mild malnutrition.

Table 1: Demographic characteristics

\begin{tabular}{lll}
\hline Variable & Level of variable & Frequency \\
\hline Age (years) & $1-2$ & $60(22.5)$ \\
& $2-3$ & $73(27.3)$ \\
& $3-4$ & $30(11.2)$ \\
Gender & $4-5$ & $23(8.6)$ \\
& Male & $101(37.7)$ \\
Mother age (years) & Female & $85(32.0)$ \\
& Less than 30 years & $95(35.7)$ \\
Education & More than 30 years & $91(34.0)$ \\
& Educated & $91(34.1)$ \\
Location & Uneducated & $95(35.6)$ \\
& Urban & $98(36.7)$ \\
Weaning time (months) & Non-urban & $88(33.0)$ \\
& Less than 4 months & $90(33.7)$ \\
& More than 4 months & $96(36.0)$ \\
\hline
\end{tabular}

\section{DISCUSSION}

Ninety $(35.7 \%)$ mothers were less than 30 years old while the age of 91 (34.0\%) mothers was 
more than 30 years and teenage pregnancies are detrimental both for mother and baby because the mother is unable to encounter the challenges of pregnancy and to provide subsequent child care including proper nutrition [13], since older mother are considered more experienced in child care [14]. Respondents from urban location 98 (36.7\%), while 88 (33.0\%). According to Gomez's classification Out of 186 children, $19(7.1 \%)$ were the victims of malnutrition, which is significantly high than that of Karachi [11]. As mentioned in Table 1, 33.7\% $(n=90)$ children are weaned before the age of 6 months while American Academy of Pediatrics (AAP) as well as World Health Organization (WHO) recommend exclusive breastfeeding at least for first six month after the birth [12] because the digestive system of the child is not so much developed before the age of 6 months. While $14.2 \%$ is in moderate and $48.3 \%$ lies in mild malnutrition the possible, the possible reasons could be the diet in this region. Unlike previous study in Karachi, there was nonsignificant $(p>0.05)$ difference in the prevalence of malnutrition between the two genders in our study. Malnourished children, belonging to various age groups are shown in Table 2.

Table 2: Classification of malnutrition in children

\begin{tabular}{lc}
\hline Gomez's classification & Frequency (\%) \\
\hline Mild Malnutrition & $129(48.3)$ \\
Moderate Malnutrition & $38(14.2)$ \\
Severe Malnutrition & $19(7.1)$ \\
\hline
\end{tabular}

Cross tabulation of results are shown in Table 3, the value was found to be significant with respect to education and weaving time, $p=0.041, p=$ 0.003 respectively. A total of $38.1 \%(n=105)$ children were in an age between 2 and 3 years, the age when the child is fed no more with breast milk, while $25 \%(n=105)$ were having age between 1 to 2 years. Out of 186, $48.3 \%$ children were suffering from mild malnutrition, $14.2 \%$ from moderate malnutrition and only 7.1 $\%$ from severe malnutrition as mentioned in Table 2.

Table 3: Cross-tabulation outcomes of data

\begin{tabular}{llc}
\hline No. & Variable & Chi-square, $\boldsymbol{p}$-value ${ }^{\text {** }}$ \\
\hline 1 & Age & 0.079 \\
2 & Gender & 0.546 \\
3 & Education & $\mathbf{0 . 0 4 1}^{\text {** }}$ \\
4 & Weave time & $\mathbf{0 . 0 0 3}^{\text {** }}$ \\
\hline
\end{tabular}

Cross tabulation results are shown in Table 3 . The value was found to be significant with respect to education and weaving time, $p=0.041$ and $p=0.003$, respectively. There is difference in the malnutrition among the malnourished children of Swat and that of Bahawalpur [10]. In our study, $64.8 \%$ of malnourished children had siblings equal to or more than five. This can be contributed to the malnutrition because family size limits the available resources including nutrition for a child that affects the nutritional status of the child [16]. Moreover, $22.8 \%$ children were not immunized, which increases the chances of diseases that in turn may lead to malnutrition.

\section{CONCLUSION}

Childhood malnutrition is not severely high in Swat region as more than half of the observed children lie in the moderate malnutrition. Moreover malnutrition has affected both the genders equally. Various risk factors have contributed in the prevalence of malnutrition. The prevalence is significantly low as compared to the other studies in Pakistan. Improving maternal and child nutritional status is prerequisite for achieving the good health status of children

\section{REFERENCES}

1. Park JE, Park K (editors). Park's textbook of Preventive of Social Medicine. 29th Edition. Jabalpur: Banarsidas Bhanol, 2007.

2. Karasalihoğlu S, Bi M, Öner N, Çeltik C, Pala Ö. Intraerythrocytic potassium levels and early insulin release in children with moderate malnutrition. J Tropical Pediatr 2003; 49: 305-307.

3. Struble M, Aomari L. Position of the American Dietetic Association: Addressing world hunger, malnutrition, and food insecurity. J Am Dietetic Assoc 2003; 103: 1046-1054.

4. Hakeem R, Thomas J, Badruddin S. Rural-urban differences in food and nutrient intake of Pakistani children. J Pak Medical Assoc 1999; 49: 288-291.

5. Walton E, Allen S. Malnutrition in developing countries. Paediatr Child Health 2011; 21: 418-424.

6. Khongsdier R. Malnutrition, social inequality and natural selection in human populations. J Hum Ecol 2006; 14: 53-67.

7. Khawar N, Kazmi NR, Barakzai AAL. Etiological factors of Malnutrition among Infants in two urban slums of Peshawar. J Post Grad Med Ins 2002; 16: 148-152.

8. Caulfield $L E$, de Onis $M$, Blössner $M$, Black RE. Undernutrition as an underlying cause of child deaths associated with diarrhea, pneumonia, malaria, and measles. Am J Clin Nutr 2004; 80: 193.

9. Martorell R, Ho TJ. Malnutrition, morbidity, and mortality. Popul Dev Rev 1984; 10: 49-68. 
10. Badar S, Channer MS, Yasmeen S. Malnutrition; determinants in children between six months to five years of age in bahawalpur. Professional Medical $J$ 2007; 14: 669-676.

11. Latif. R. Malnutrition in children in the low socioeconomic area of Karachi. Pak Pediatr J 2007; 31: 53-57.

12. Li R, Zhao Z, Mokdad A, Barker L, Grummer-Strawn L. Prevalence of breastfeeding in the United States: The 2001 National Immunization Survey. Pediatr 2003; 111: 1198-1207.

13. LeGrand TK, Mbacké CSM. Teenage pregnancy and child health in the urban Sahel. Stud. Fam. Plan. 1993: 12: $137-149$.
14. Kassouf AL, Senauer B. Direct and indirect effects of parental education on malnutrition among children in Brazil: a full income approach. Econ Develop Cultural Change 1996; 44: 817-38.

15. Victora CG, Vaughan JP, Kirkwood BR, Martines JC, Barcelos LB. Risk factors for malnutrition in Brazilian children: the role of social and environmental variables. Bull World Health Org 1986; 64: 299-307.

16. Blake J. Family size and the quality of children. Demograph 1981; 18: 421-442. 